\title{
Fasting and Non-Fasting Triglycerides and Risk of Cardiovascular Events in Diabetic Patients Under Statin Therapy
}

\author{
Hayato Tada, MD; Akihiro Nomura, MD; Kenichi Yoshimura, PhD; \\ Hiroshi Itoh, MD; Issei Komuro, MD; Masakazu Yamagishi, MD; \\ Masayuki Takamura, MD; Masa-aki Kawashiri, MD
}

\begin{abstract}
Background: Few data specifically investigate associations between fasting/non-fasting triglycerides (TG) and cardiovascular (CV) events under statin therapy among Japanese diabetic patients.

Methods and Results: We recruited 4,988 participants with diabetes from the EMPATHY study. Median follow-up was 3 years. We evaluated associations between serum fasting/non-fasting TG and first CV events in Cox-regression hazard models adjusted by classical risk factors. CV events were defined as (1) major adverse cardiac events (MACE) including myocardial infarction, stroke, or cardiac death; and (2) CV diseases (CVD) including myocardial infarction, unstable angina, ischemic stroke, or large artery disease or peripheral arterial disease. Fasting as well as non-fasting TG were associated with MACE (adjusted hazard ratio [HR]: 1.017 per $10 \mathrm{mg} / \mathrm{dL} ; 95 \%$ confidence interval [Cl]: 1.000-1.037; $\mathrm{P}=0.046$, adjusted HR: 1.028 per $10 \mathrm{mg} / \mathrm{dL} ; 95 \% \mathrm{Cl}: 1.006-1.050 ; \mathrm{P}=0.0091$ ) and CVD (adjusted HR: 1.024 per $10 \mathrm{mg} / \mathrm{dL} ; 95 \% \mathrm{Cl}: 1.011-1.038 ; \mathrm{P}=4.4 \times 10^{-3}$, adjusted HR: 1.028 per $10 \mathrm{mg} / \mathrm{dL} ; 95 \% \mathrm{Cl}: 1.010-$ 1.046; $\left.\mathrm{P}=4.9 \times 10^{-3}\right)$. Comparing the top quartile with the bottom quartile of non-fasting $\mathrm{TG}$, adjusted $\mathrm{HR}$ significantly increased 5.18 (95\% Cl: 1.38-18.3, $\mathrm{P}=0.014)$ for MACE, and $2.40(95 \% \mathrm{Cl}: 1.11-4.75, \mathrm{P}=0.021)$ for $\mathrm{CVD}$, while adjusted HR did not change when divided into quartile of fasting $\mathrm{TG}$.
\end{abstract}

Conclusions: Non-fasting TG could be considered as a substitute for fasting TG as a risk stratification for future CV events among Japanese diabetic patients.

Key Words: Cardiovascular disease; Residual risk; Statins; Triglycerides

$\mathbf{P}$ atients with hypercholesterolemia and diabetes mellitus (DM), especially complicated by diabetic retinopathy, are considered to be high-risk for cardiovascular (CV) events. ${ }^{\mathbf{1} 2}$ We have previously shown that intensive low-density lipoprotein (LDL)-lowering therapy, targeting LDL cholesterol (LDL-C) $<70 \mathrm{mg} / \mathrm{dL}$ was superior to standard therapy targeting LDL-C $<120 \mathrm{mg} / \mathrm{dL}$, ${ }^{3}$ and that serum triglycerides (TG) were a residual risk factor for $\mathrm{CV}$ events among such patients treated using statins. ${ }^{4}$ In addition to our data, another group have clearly shown that there is a substantial proportion of individuals with hypertriglyceridemia not eligible for statin therapy according to current guidelines, despite their similar risk for ASCVD to statin-eligible individuals. ${ }^{5}$ Moreover, recent Mendelian randomization studies have repeatedly shown that TG seem to be causally associated with $\mathrm{CV}$ diseases

\section{Editorial p 386}

(CVD), ${ }^{6}$ leading to our consensus that serum TG should be a major residual target in addition to statin therapy for preventive cardiology.

The current Japanese guideline for preventive CVD adopts fasting $\mathrm{TG}^{7}$ because of the lack of data regarding the clinical impact of non-fasting $\mathrm{TG}$ on $\mathrm{CV}$ events in Japanese, which typically increased postprandially. ${ }^{8}$ On the other hand, recent guidelines for preventive cardiology in Europe accept the assessments of non-fasting $\mathrm{TG}^{9}$ based on investigations showing that non-fasting TG probably reflect increases of atherogenic post-prandial remnant lipoproteins associated with increased risk for CVD. ${ }^{10-12}$

Here, we tested whether fasting as well as non-fasting

Received November 6, 2019; revised manuscript received December 16, 2019; accepted December 27, 2019; J-STAGE Advance Publication released online February 6, 2020 Time for primary review: 26 days

Department of Cardiology, Kanazawa University Graduate School of Medicine, Kanazawa (H.T., A.N., M.T., M.K.); Innovative Clinical Research Center, Kanazawa University, Kanazawa (A.N., K.Y.); Department of Endocrinology, Metabolism and Nephrology, Keio University School of Medicine, Tokyo (H.I.); Department of Cardiovascular Medicine, The University of Tokyo Graduate School of Medicine, Tokyo (I.K.); and Osaka University of Human Sciences, Osaka (M.Y.), Japan

Mailing address: Hayato Tada, MD, PhD, Department of Cardiology, Kanazawa University Graduate School of Medicine, 13-1 Takara-machi, Kanazawa 920-8641, Japan. E-mail: ht240z@sa3.so-net.ne.jp

ISSN-1346-9843 All rights are reserved to the Japanese Circulation Society. For permissions, please e-mail: cj@j-circ.or.jp 
Table 1. Baseline Characteristics of Patients Whose Lipids Were Measured in the Fasting State

\begin{tabular}{|c|c|c|c|c|c|}
\hline \multirow[b]{2}{*}{ Variable } & \multicolumn{5}{|c|}{ Fasting } \\
\hline & $\begin{array}{c}\text { All } \\
(n=3,150)\end{array}$ & $\begin{array}{c}\text { Quartile 1 } \\
\text { [28-82 mg/dL] } \\
(\mathrm{n}=806)\end{array}$ & $\begin{array}{c}\text { Quartile 2 } \\
\text { [83-112 mg/dL] } \\
\text { (n=792) }\end{array}$ & $\begin{array}{c}\text { Quartile 3 } \\
\text { [113-159 mg/dL] } \\
(n=768)\end{array}$ & $\begin{array}{c}\text { Quartile } 4 \\
{[160-1,340 \mathrm{mg} / \mathrm{dL}]} \\
(\mathrm{n}=784)\end{array}$ \\
\hline Age (years) & $63 \pm 11$ & $63 \pm 10$ & $63 \pm 11$ & $63 \pm 11$ & $61 \pm 11$ \\
\hline Male (\%) & $1,529(49)$ & $379(47)$ & $370(47)$ & $355(46)$ & $425(54)$ \\
\hline $\mathrm{BMI}\left(\mathrm{kg} / \mathrm{m}^{2}\right)$ & $25.7 \pm 4.3$ & $24.4 \pm 4.1$ & $25.4 \pm 4.3$ & $26.3 \pm 4.3$ & $26.9 \pm 4.3$ \\
\hline $\mathrm{HbA1c}(\%)$ & $7.8 \pm 1.3$ & $7.7 \pm 1.3$ & $7.8 \pm 1.4$ & $7.9 \pm 1.3$ & $8.0 \pm 1.2$ \\
\hline Current smoking (\%) & $590(19)$ & $106(13)$ & $137(17)$ & 149 (19) & $198(25)$ \\
\hline Hypertension (\%) & $2,236(71)$ & $530(66)$ & $554(70)$ & $558(73)$ & $594(76)$ \\
\hline LDL-C (mg/dL) & $110 \pm 26$ & $102 \pm 23$ & $109 \pm 25$ & $113 \pm 25$ & $117 \pm 28$ \\
\hline $\mathrm{HDL}-\mathrm{C}(\mathrm{mg} / \mathrm{dL})$ & $56 \pm 14$ & $64 \pm 15$ & $58 \pm 14$ & $53 \pm 11$ & $49 \pm 12$ \\
\hline MACE (\%) & $70(2)$ & $15(2)$ & $13(2)$ & $21(3)$ & $21(3)$ \\
\hline CVD (\%) & $118(4)$ & $22(3)$ & $21(3)$ & $37(5)$ & $38(5)$ \\
\hline Intensive therapy (\%) & $1,579(50)$ & 394 (49) & $414(52)$ & $384(50)$ & $387(49)$ \\
\hline
\end{tabular}

BMI, body mass index; CVD, cardiovascular diseases; HDL-C, high-density lipoprotein cholesterol; LDL-C, low-density lipoprotein cholesterol; MACE, major adverse cardiac events.

\begin{tabular}{|c|c|c|c|c|c|}
\hline \multirow[b]{2}{*}{ Variable } & \multicolumn{5}{|c|}{ Non-fasting } \\
\hline & $\begin{array}{c}\text { All } \\
(n=1,838)\end{array}$ & $\begin{array}{c}\text { Quartile } \\
{[32-92 \mathrm{mg} / \mathrm{dL}]} \\
(\mathrm{n}=460)\end{array}$ & $\begin{array}{c}\text { Quartile } 2 \\
\text { [93-131 mg/dL] } \\
(n=467)\end{array}$ & $\begin{array}{c}\text { Quartile 3 } \\
\text { [132-186 mg/dL] } \\
(\mathrm{n}=456)\end{array}$ & $\begin{array}{c}\text { Quartile } 4 \\
{[187-1,500 \mathrm{mg} / \mathrm{dL}]} \\
(\mathrm{n}=455)\end{array}$ \\
\hline Age (years) & $64 \pm 10$ & $65 \pm 10$ & $64 \pm 10$ & $63 \pm 11$ & $61 \pm 11$ \\
\hline Male (\%) & $853(46)$ & 217 (47) & $213(46)$ & $205(45)$ & $218(48)$ \\
\hline BMI $\left(\mathrm{kg} / \mathrm{m}^{2}\right)$ & $25.5 \pm 4.2$ & $24.1 \pm 4.0$ & $25.2 \pm 4.2$ & $26.0 \pm 4.1$ & $26.5 \pm 4.1$ \\
\hline $\mathrm{HbA1c}(\%)$ & $7.9 \pm 1.3$ & $7.8 \pm 1.1$ & $8.0 \pm 1.3$ & $7.9 \pm 1.3$ & $8.1 \pm 1.4$ \\
\hline Current smoking (\%) & 346 (19) & $71(15)$ & $84(18)$ & $90(20)$ & $101(22)$ \\
\hline Hypertension (\%) & $1,305(71)$ & 307 (67) & $337(72)$ & $327(72)$ & 334 (73) \\
\hline LDL-C (mg/dL) & $109 \pm 25$ & $101 \pm 23$ & $108 \pm 25$ & $112 \pm 25$ & $113 \pm 26$ \\
\hline HDL-C (mg/dL) & $55 \pm 13$ & $63 \pm 14$ & $57 \pm 13$ & $52 \pm 11$ & $48 \pm 11$ \\
\hline MACE (\%) & $42(2)$ & $3(1)$ & $11(2)$ & $12(3)$ & $16(4)$ \\
\hline CVD (\%) & $68(4)$ & $12(3)$ & $10(2)$ & $23(5)$ & $23(5)$ \\
\hline Intensive therapy (\%) & $914(50)$ & 217 (47) & $218(47)$ & $235(52)$ & $244(54)$ \\
\hline
\end{tabular}

Abbreviations as in Table 1.

TG were associated with first CV events under effective statin treatment in high-risk diabetic patients in the standard vs. intEnsive statin therapy for hypercholesteroleMic Patients with diAbetic retinopaTHY (EMPATHY) study as a posthoc analysis.

\section{Methods}

\section{Study Population}

The EMPATHY study was conducted to determine whether intensive lipid-lowering therapy is superior to standard therapy in reducing the incidence of CV events or death from CV events in patients with hyperlipidemia and diabetic retinopathy and without a history of CVD. The study used a multicenter, prospective, randomized, openlabel, blinded endpoint design. It was conducted in Japan in accordance with the Declaration of Helsinki and Japanese ethical guidelines for clinical studies, and was registered with the University Hospital Medical Information clinical trials registry (UMIN000003486). In The EMPATHY study, eligible high-risk patients were randomly assigned in a $1: 1$ ratio to receive intensive or standard statin therapy targeted to reducing LDL-C by $<70 \mathrm{mg} / \mathrm{dL}$ or $\geq 100$ and $<120 \mathrm{mg} / \mathrm{dL}$. We excluded 56 patients whose information regarding the timing of assessments of serum lipids were unclear, then included 3,150 patients measured in the fasting state as well as 1,838 patients measured in the non-fasting state. LDL-C levels were calculated using the Friedewald formula if TG levels were $<400 \mathrm{mg} / \mathrm{dL}$; otherwise, they were determined enzymatically. Detailed information was described previously. ${ }^{13}$

\section{Endpoints}

In this posthoc analysis of EMPATHY trial, we defined major adverse cardiac events (MACE) as the composite endpoint including myocardial infarction, stroke (ischemic, hemorrhagic, or subarachnoid), or death associated with $\mathrm{CV}$ events. In contrast, CVD were defined as the composite endpoint including myocardial infarction, unstable angina, ischemic stroke, or aortic disease or peripheral arterial disease. We used the lipid parameters at baseline just before randomization. Details are described previously. ${ }^{\mathbf{1 3}}$ 

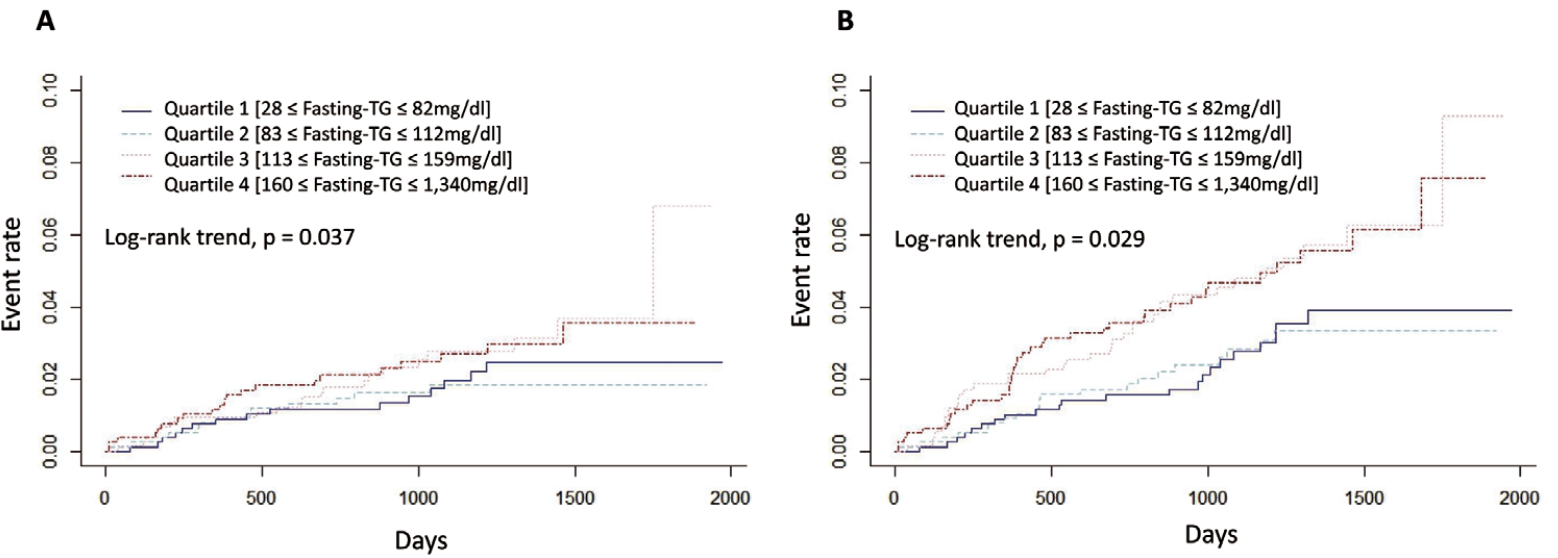

Figure 1. Cumulative incidence of (A) major adverse cardiac events (MACE), and (B) cardiovascular disease (CVD) according to quartile of fasting triglycerides.

A

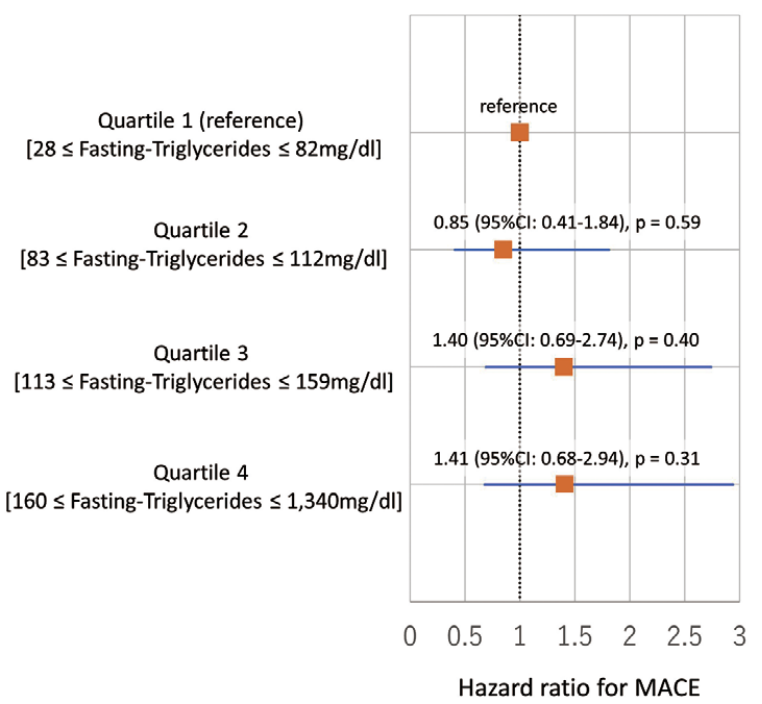

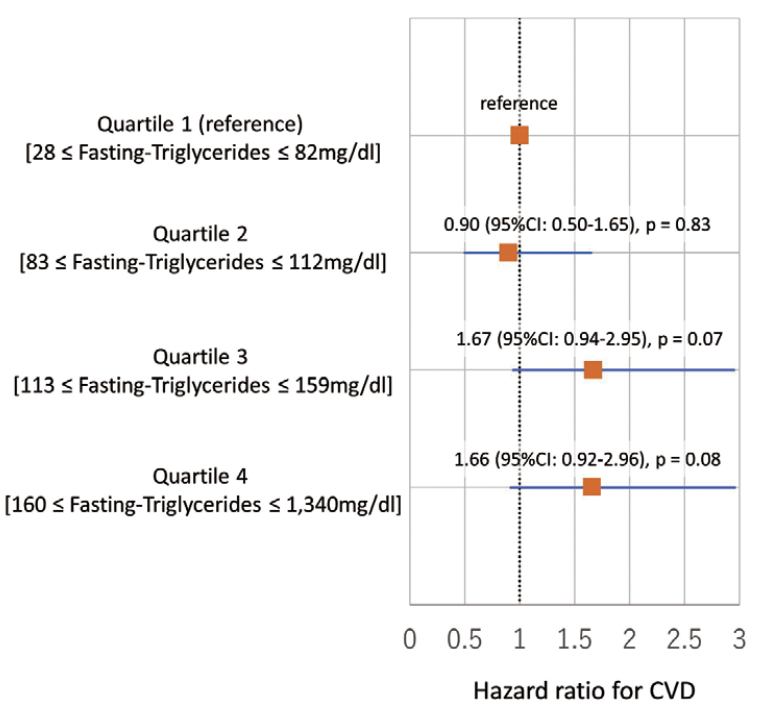

Figure 2. Impact of fasting triglycerides on major adverse cardiac events (MACE) and cardiovascular disease (CVD). Forrest plot of hazard ratio for (A) MACE and (B) CVD.

\section{Ethical Considerations}

The study was approved by the Ethics Committee of Kanazawa University. All procedures followed were in accordance with the ethical standards of the responsible committee on human experimentation (institutional and national) and with the Helsinki Declaration of 1975, as revised in 2008. Informed consent for genetic analyses was given by all of the subjects included in the study.

\section{Statistical Analysis}

Hazard ratios (HR) were determined adjusted for age, sex, body mass index (BMI), HbAlc, hypertension, current smoking, LDL-C, and treatment assignment. The distribution of TG levels at baseline is described in quartiles. HR for the occurrence of endpoint events were calculated in 2 ways: dealing with TG as a continuous variable $(10 \mathrm{mg} / \mathrm{dL}$ increment), or categorical variable (with quartile 1 serving as the referent group). We also checked the interactions of hazards for both events when stratified by age, and sex. The cumulative fraction of events was estimated as 1 minus the Kaplan-Meier estimate of survival free of the event. The differences in the cumulative fraction of events between subgroups were assessed by the log-rank test. C-statistics were compared by the method of DeLong et al. ${ }^{14}$ All statistical analyses were conducted using $\mathrm{R}$ statistical software (version 3.3.3; www.R-project.org). 

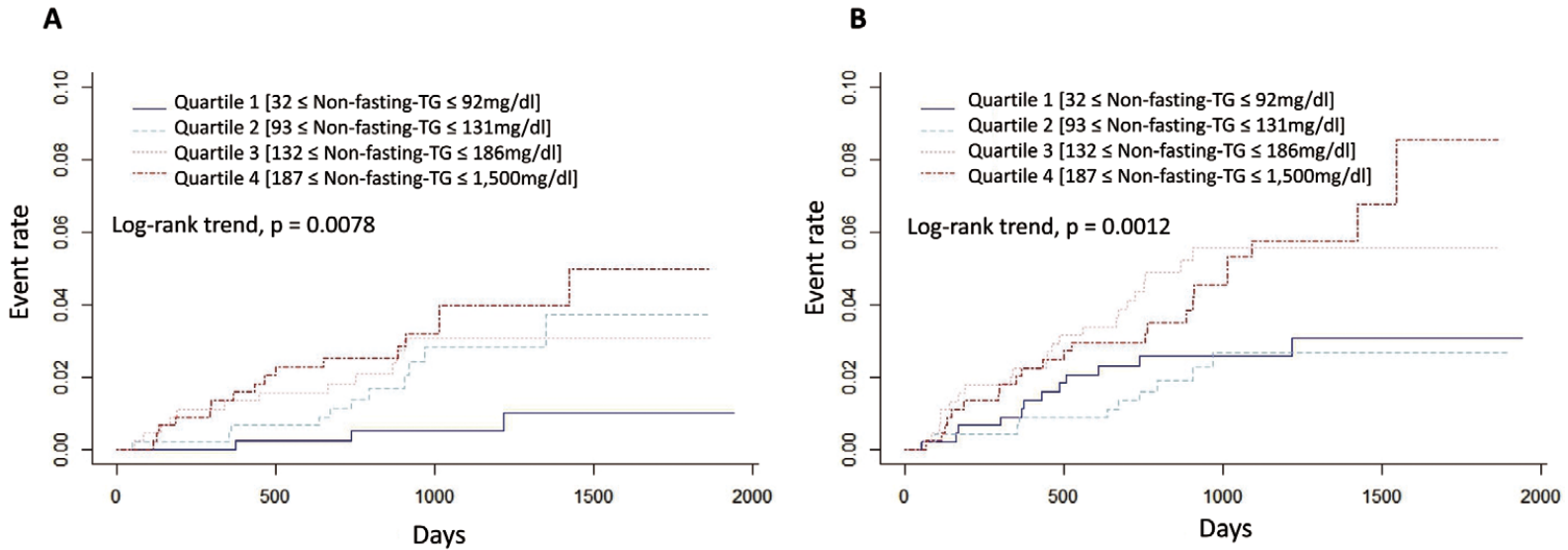

Figure 3. Cumulative incidence of (A) major adverse cardiac events (MACE), and (B) cardiovascular disease (CVD) according to quartile of non-fasting triglycerides.

A

Quartile 1 (reference)

$[32 \leq$ Non-fasting-Triglycerides $\leq 92 \mathrm{mg} / \mathrm{dl}]$

Quartile 2

[93 $\leq$ Non-fasting-Triglycerides $\leq 131 \mathrm{mg} / \mathrm{dl}]$

Quartile 3

[132 $\leq$ Non-fasting-Triglycerides $\leq 186 \mathrm{mg} / \mathrm{dl}]$

Quartile 4

[187 $\leq$ Non-fasting-Triglycerides $\leq 1,500 \mathrm{mg} / \mathrm{dl}]$

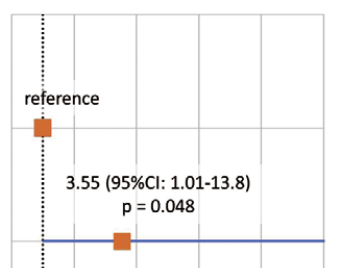

[93 $\leq$ Non-fasting-Triglycerides $\leq 131 \mathrm{mg} / \mathrm{dl}$ ]

Quartile 3

[132 $\leq$ Non-fasting-Triglycerides $\leq 186 \mathrm{mg} / \mathrm{dl}]$

Quartile 4

[187 $\leq$ Non-fasting-Triglycerides $\leq 1,500 \mathrm{mg} / \mathrm{dl}]$

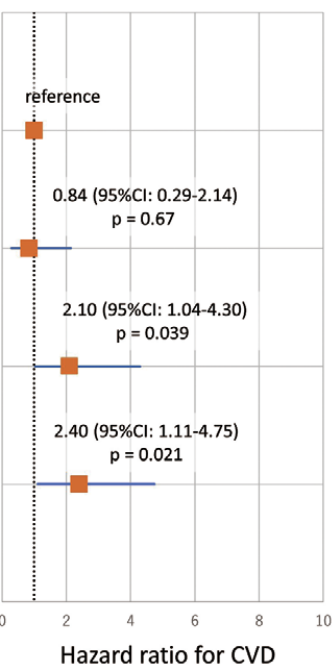

Figure 4. Impact of non-fasting triglycerides on major adverse cardiac events (MACE) and cardiovascular disease (CVD). Forrest plot of hazard ratio for (A) MACE and (B) CVD.

\section{Results}

\section{Characteristics of the Study Subjects}

Characteristics are summarized in Table 1, and Table 2. Detailed descriptions were given previously. ${ }^{13}$ In brief, data from 4,988 patients were analyzed, including data for 2,493 patients in the intensive therapy group and 2,495 patients in the standard therapy group. When the patients were divided into quartiles of fasting or non-fasting TG, there were significant trends in BMI, current smoking, hypertension, LDL-C, high-density lipoprotein cholesterol, and CVD among both groups (fasting and non-fasting), whereas there was no significant trend in MACE in the fasting group (Tables 1,2).

\section{Associations Between Fasting TG and MACE/CVD}

During a median 3-year follow-up period in the EMPATHY study, 70 patients $(2 \%)$ had at least 1 MACE, and 118 patients $(4 \%)$ had at least $1 \mathrm{CV}$ event among those whose TG were measured in the fasting state. The cumulative incidences of MACE and CVD divided by the quartile of fasting TG are illustrated in Figure 1. Risk increased across quintiles of fasting TG for MACE and CVD $(\mathrm{P}=0.037$, 0.029 , respectively). A $10-\mathrm{mg} / \mathrm{dL}$ increment in fasting TG was associated with HR of 1.017 (95\% CI: $1.000-1.037$; $\mathrm{P}=0.046$, Supplementary Table 1) for MACE, HR of 1.024 (95\% CI: $1.011-1.038 ; \mathrm{P}=4.4 \times 10^{-3}$, Supplementary Table 1), for CVD under adjustment for age, sex, BMI, HbAlc, hypertension, current smoking, LDL-C, and treatment 


\section{A}

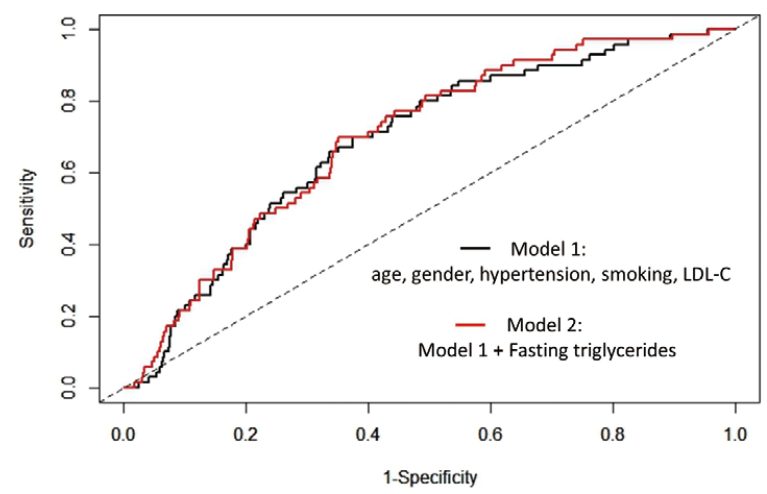

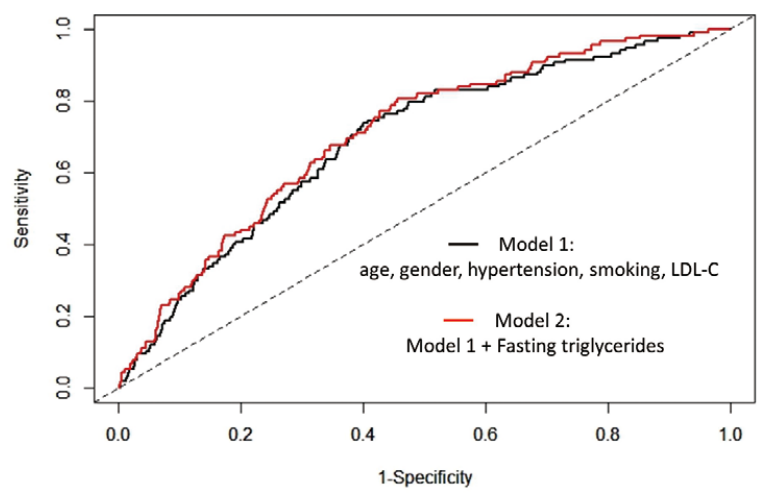

Figure 5. Receiver-operating characteristic curves predicting (A) major adverse cardiac events (MACE) and (B) cardiovascular disease (CVD). LDL-C, low-density lipoprotein cholesterol.

A

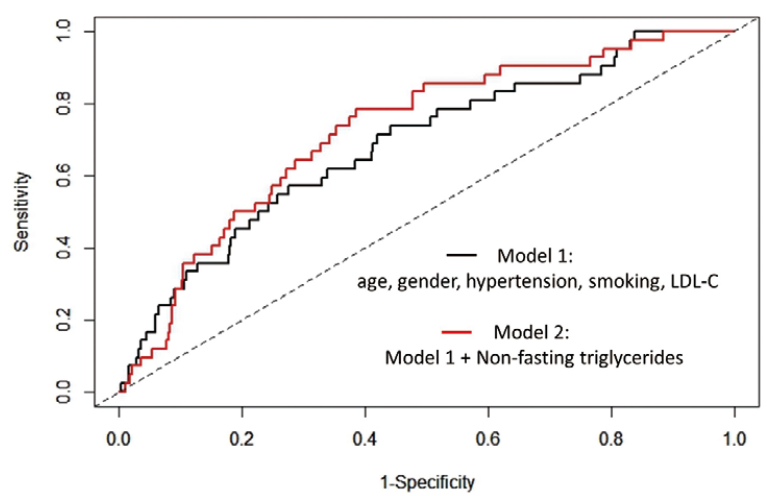

B

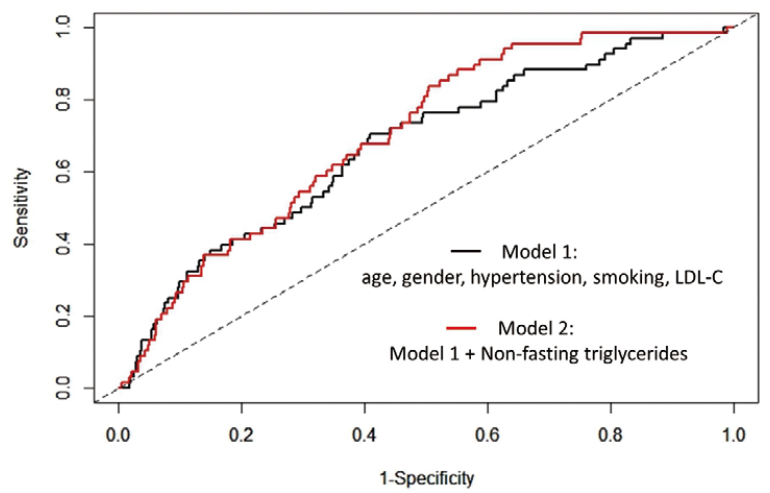

Figure 6. Receiver-operating characteristic curves predicting (A) major adverse cardiac events (MACE) and (B) cardiovascular disease (CVD). LDL-C, low-density lipoprotein cholesterol.

assignment. Relative to the lowest quartile $(\leq 82 \mathrm{mg} / \mathrm{dL})$, risk in the highest quartile of fasting TG $(\geq 160 \mathrm{mg} / \mathrm{dL})$ for MACE was 1.41 (95\% CI: 0.68-2.94, $\mathrm{P}=0.59$, Figure 2A), and that for CVD was 1.66 (95\% CI: $0.92-2.96, \mathrm{P}=0.08$, Figure 2B).

\section{Associations Between Non-Fasting TGs and MACE/CVD}

During a median 3-year follow-up period in the EMPATHY study, 42 patients $(2 \%)$ had at least 1 MACE, and 68 patients $(4 \%)$ had at least $1 \mathrm{CV}$ event among those whose TG were measured in the non-fasting state. The cumulative incidences of MACE and CVD divided by the quartile of non-fasting TG are illustrated in Figure 3. Risk increased across quintiles of fasting TG for MACE and CVD ( $\mathrm{P}=0.0078,0.0012$, respectively). A $10-\mathrm{mg} / \mathrm{dL}$ increment in non-fasting TG was associated with HR of $1.028(95 \%$ CI: $1.006-1.050 ; \mathrm{P}=0.0091$, Supplementary Table 2) for MACE, HR of 1.028 (95\% CI: $1.010-1.046 ; \mathrm{P}=4.9 \times 10^{-3}$, Supplementary Table 2), for CVD under adjustment for age, sex, BMI, HbA1c, hypertension, current smoking, LDL-C, and treatment assignment. Relative to the lowest quartile $(\leq 92 \mathrm{mg} / \mathrm{dL})$, risk in the highest quartile of non-fasting TG $(\geq 187 \mathrm{mg} / \mathrm{dL})$ for MACE was 5.18 (95\% CI: $1.38-18.3$, $\mathrm{P}=0.014$, Figure 4A), and that for CVD was $2.40(95 \% \mathrm{CI}$ : $1.11-4.75, \mathrm{P}=0.021$, Figure 4B).

\section{Influence by Age, and Sex}

We further added analyses stratified by age, and sex. There was no significant difference in the associations between fasting as well as non-fasting TG and CV events when stratified by median age (Supplementary Table 3). Interestingly, we found that non-fasting TG exhibited greater associations with future events in females compared with males, but we did not find such a difference in fasting TG (Supplementary Table 4).

\section{Risk Discrimination by Fasting or Non-Fasting TG}

We investigated whether the discrimination of a model 
based on basic traditional risk factors comprising age, sex, hypertension, current smoking and LDL-C differed from that of a model that also included fasting or non-fasting TG. For the prediction of MACE as well as CVD, the c-statistic for the traditional risk factors model (model 1) was 0.688 (95\% CI: $0.632-0.745)$ and 0.690 (95\% CI: 0.644 $0.736)$, respectively. They did not increase significantly to 0.697 (95\% CI: $0.643-0.751, P=0.31$, Figure 5A), and 0.708 (95\% CI: $0.662-0.752, \mathrm{P}=0.12$, Figure 5B) after the addition of fasting TG to the model 1 (model 2). On the other hand, the addition of non-fasting TG to traditional risk factors (model 1) increased the c-statistics significantly from 0.686 (95\% CI: $0.604-0.767)$ and 0.672 (95\% CI: $0.608-0.736)$ to 0.724 (95\% CI: $0.652-0.797)$ and 0.712 (95\% CI: 0.648 $0.757)$, for MACE $(P=0.033$, Figure 6A $)$ and $\operatorname{CVD}(P=0.047$, Figure 6B), respectively.

\section{Discussion}

In the current study, we found that fasting as well as non-fasting TG were associated with MACE as well as with CVD regardless of the intensity of statin therapy in high-risk patients with hypercholesterolemia and diabetic retinopathy. Moreover, we found that non-fasting TG rather than fasting TG were more useful for risk discrimination for future MACE and CV events. This is one of the largest studies specifically investigating the association between fasting as well as non-fasting TG and CVD under effective treatment using statins in Japanese diabetic patients. Our findings strongly support the idea that non-fasting TG, which reflect elevation of post-prandial remnant lipoproteins, could be acceptable for risk assessment of CVD among high-risk Japanese diabetic patients, especially females, under effective statin therapy.

The lipid profile is conventionally measured after fasting for at least $8 \mathrm{~h}$, and, therefore may not reflect the daily average plasma lipid and lipoprotein concentrations and associated risk for CVD. On the other hand, measuring TG in the post-prandial state has several advantages over the fasting state. Subjects are in a post-prandial state for most of the day, which allows blood sampling without the need for fasting. In addition, fasting blood sampling is often the standard in daily risk assessment to follow evidencebased practice, because many randomized lipid-lowering trials have used fasting lipid measurements. However, many population-based studies and some major statin trials used random, non-fasting blood sampling, providing a robust evidence base for changing the conventional practice of using fasting samples. ${ }^{15,16}$ In addition, in most of the Mendelian randomization and association studies focusing on the association between TG and ASCVD outcomes, TG levels were mainly measured in a non-fasting state. ${ }^{6,17}$ Therefore, the European Atherosclerosis Society/European Federation of Clinical Chemistry and Laboratory Medicine (EAS/EFLM)'s joint consensus statement recommended that non-fasting blood samples should be routinely used for plasma lipid profile assessments. ${ }^{18} \mathrm{~A}$ few years ago, an important paper specifically investigating the clinical impact of fasting as well as non-fasting TG on ischemic CVD using a population-based cohort showed the usefulness of non-fasting TG in Japanese as well. ${ }^{19}$ Our present study has a couple of strengths compared with that study. The EMPATHY study is a clinical trial that only included diabetic patients with retinopathy where all the patients were under statin therapy. And overcoming "residual risk" during this statin era can still be an important issue. ${ }^{20}$ Accordingly, we want to emphasize that non-fasting TG are residual risk among such patients. In addition, all the events in the EMPATHY study had detailed definitions, and were evaluated by an independent committee. Our results from a posthoc analysis of a prospective randomized controlled trial have added strong evidence that non-fasting TG are useful for CV risk assessments among Japanese diabetic patients.

In addition to these results, we found that non-fasting TG had better predictive value in females compared with males. The underlying mechanism of this phenomenon is unclear; however, our findings appear to be consistent with previous findings. ${ }^{\mathbf{1 0}, 11,19}$

Regarding the management target of TG, no study exists that specifically investigated this issue or compared directly fasting and non-fasting TG among the same Japanese individuals. However, we would suggest changing the current treatment target of TG from fasting TG $<150 \mathrm{mg} / \mathrm{dL}$ to fasting TG $<113 \mathrm{mg} / \mathrm{dL}$ or non-fasting TG $<132 \mathrm{mg} / \mathrm{dL}$ according to our results showing the marked increase at those values.

\section{Study Limitations}

The study population was Japanese middle-aged to elderly individuals; hence, generalizability to other ethnicities or age groups is uncertain. However, the trend of an unfavorable relationship between fasting as well as non-fasting TG and CVD, consistent with previous studies, suggests that our main conclusion could be applicable to other ethnicities or age groups. In addition, we did not account for medical therapy for DM, which could affect TG. However, we believe that our relatively large sample size would dilute this potential bias, and that most diabetic agents used in this study have not been associated with risk reduction of CVD in a few years. This study focused only on diabetic patients with retinopathy, which is a subgroup of DM. Accordingly, our results may not be applicable to DM patients without retinopathy. Although TG are known to exhibit skewed distribution, we did not transform the values, because we believe that transformed $\mathrm{TG}$ values have little clinical relevance. In this study, we did not have enough information regarding the exact timing of blood draw (we only know fasting or non-fasting). Measurements of postprandial TG (non-fasting TG), especially at 3-4h after a meal may well provide relevant information on vascular risk than measurements of fasting TG. ${ }^{\mathbf{8}}$ Further studies that assess the exact timing of the measurements are needed. Finally, we hope that studies using new drugs that could effectively reduce serum TG will illuminate the beneficial effects of preventing $\mathrm{CV}$ events in patients with hypercholesterolemia and diabetic retinopathy treated with statins.

\section{Conclusions}

Non-fasting as well as fasting TG were associated with first $\mathrm{CV}$ events among high-risk DM patients under statin therapy. Non-fasting TG could be considered as a substitute for fasting $\mathrm{TG}$ for risk stratification of future CV events among such patients.

\section{Sources of Funding}




\section{Disclosures}

M.Y. reports a research grant from Kowa Co., Ltd. H.I. reports grants and personal fees from Takeda Pharmaceutical Company Limited, and Mochida Pharmaceutical Co., Ltd. I.K. reports grants and personal fees from Takeda Pharmaceutical Company Limited. None of the other authors has anything to disclose.

\section{References}

1. Kannel WB. Lipids, diabetes, and coronary heart disease: Insights from the Framingham Study. Am Heart J 1985; 110: 1100-1107.

2. Xie J, Ikram MK, Cotch MF, Klein B, Varma R, Shaw JE, et al. Association of diabetic macular edema and proliferative diabetic retinopathy with cardiovascular disease: A systematic review and meta-analysis. JAMA Ophthalmol 2017; 135: 586-593.

3. Itoh H, Komuro I, Takeuchi M, Akasaka T, Daida H, Egashira Y, et al. Intensive treat-to-target statin therapy in high-risk Japanese patients with hypercholesterolemia and diabetic retinopathy: Report of a randomized study. Diabetes Care 2018; 41: 12751284.

4. Tada H, Kawashiri MA, Nomura A, Yoshimura K, Itoh H, Komuro I, et al. Serum triglycerides predict first cardiovascular events in diabetic patients with hypercholesterolemia and retinopathy. Eur J Prev Cardiol 2018; 25: 1852-1860.

5. Madsen CM, Varbo A, Nordestgaard BG. Unmet need for primary prevention in individuals with hypertriglyceridaemia not eligible for statin therapy according to European Society of Cardiology/European Atherosclerosis Society guidelines: A contemporary population-based study. Eur Heart J 2018; 39: $610-619$.

6. Tada H, Kawashiri MA. Genetic variations, triglycerides, and atherosclerotic disease. J Atheroscler Thromb 2019; 26: 128-131.

7. Teramoto T, Sasaki J, Ishibashi S, Birou S, Daida H, Dohi S, et al. Executive summary of the Japan Atherosclerosis Society (JAS) guidelines for the diagnosis and prevention of atherosclerotic cardiovascular diseases in Japan: 2012 version. J Atheroscler Thromb 2014; 21: 296-298.

8. Tada H, Nohara A, Inazu A, Mabuchi H, Kawashiri MA. Remnant lipoproteins and atherosclerotic cardiovascular disease. Clin Chim Acta 2019; 490: 1-5.

9. Catapano AL, Graham I, De Backer G, Wiklund O, Chapman MJ, Drexel H, et al. 2016 ESC/EAS guidelines for the management of dyslipidaemias. Eur Heart J 2016; 37: 2999-3058.

10. Bansal S, Buring JE, Rifai N, Mora S, Sacks FM, Ridker PM. Fasting compared with nonfasting triglycerides and risk of cardiovascular events in women. JAMA 2007; 298: 309-316.

11. Freiberg JJ, Tybjaerg-Hansen A, Jensen JS, Nordestgaard BG. Nonfasting triglycerides and risk of ischemic stroke in the general population. JAMA 2008; 300: 2142-2152.
12. Jørgensen AB, Frikke-Schmidt R, West AS, Grande P, Nordestgaard BG, Tybjærg-Hansen A. Genetically elevated non-fasting triglycerides and calculated remnant cholesterol as causal risk factors for myocardial infarction. Eur Heart $J$ 2013; 34: $1826-1833$.

13. Ueshima K, Itoh H, Kanazawa N, Komuro I, Nagai R, Takeuchi $\mathrm{M}$, et al. Rationale and design of the standard versus intensive statin therapy for hypercholesterolemic patients with diabetic retinopathy (EMPATHY) study: A randomized controlled trial. J Atheroscler Thromb 2016; 23: 976-990.

14. DeLong ER, DeLong DM, Clarke-Pearson DL. Comparing the areas under two or more correlated receiver operating characteristic curves: A nonparametric approach. Biometrics 1988; 44: $837-845$.

15. Sever PS, Dahlöf B, Poulter NR, Wedel H, Beevers G, Caulfield M, et al. Prevention of coronary and stroke events with atorvastatin in hypertensive patients who have average or lower-than-average cholesterol concentrations, in the Anglo-Scandinavian Cardiac Outcomes Trial-Lipid Lowering Arm (ASCOT-LLA): A multicentre randomised controlled trial. Lancet 2003; 361: 1149-1158.

16. SEARCH Study Collaborative Group, Bowman L, Armitage J, Bulbulia R, Parish S, Collins R. Study of the effectiveness of additional reductions in cholesterol and homocysteine (SEARCH): Characteristics of a randomized trial among 12064 myocardial infarction survivors. Am Heart J 2007; 154: 815-823.

17. TG and HDL Working Group of the Exome Sequencing Project, National Heart, Lung, and Blood Institute, Crosby J, Peloso GM, Auer PL, Crosslin DR, Stitziel NO, Lange LA, et al. Loss-offunction mutations in APOC3, triglycerides, and coronary disease. N Engl J Med 2014; 371: 22-31.

18. Nordestgaard BG, Langsted A, Mora S, Kolovou G, Baum H, Bruckert $\mathrm{E}$, et al. Fasting is not routinely required for determination of a lipid profile: Clinical and laboratory implications including flagging at desirable concentration cut-points. A joint consensus statement from the European Atherosclerosis Society and European Federation of Clinical Chemistry and Laboratory Medicine. Eur Heart J 2016; 37: 1944-1958.

19. Iso H, Imano H, Yamagishi K, Ohira T, Cui R, Noda H, et al. Fasting and non-fasting triglycerides and risk of ischemic cardiovascular disease in Japanese men and women: The Circulatory Risk in Communities Study (CIRCS). Atherosclerosis 2014; 237: 361-368.

20. Cho KI, Yu J, Hayashi T, Han SH, Koh KK. Strategies to overcome residual risk during statins era. Circ J 2019; 83: 1973 1979.

\section{Supplementary Files}

Please find supplementary file(s);

http://dx.doi.org/10.1253/circj.CJ-19-0981 